\title{
Designing instruction for complex learning: 4C/ID in higher education
}

\author{
Jimmy Frerejean ${ }^{1}$ | Jeroen J.G. van Merriënboer ${ }^{1}$ | Paul A. Kirschner ${ }^{2,3}$ \\ Ann Roex $^{4}$ | Bert Aertgeerts ${ }^{5}$ | Marco Marcellis ${ }^{6}$
}

${ }^{1}$ School of Health Professions

Education, Faculty of Health, Medicine and Life Sciences, Maastricht University, Maastricht, the Netherlands

${ }^{2}$ Open University of the Netherlands, Heerlen, The Netherlands

${ }^{3}$ LET Research Unit, University of Oulu, Oulu, Finland

${ }^{4}$ Department of Clinical Sciences, Faculty of Medicine and Pharmacy, VUB, Jette, Belgium

${ }^{5}$ Department of Public Health and Primary Care, KU Leuven, Leuven, Belgium

${ }^{6}$ Faculty of Digital Media and Creative Industries, Amsterdam University of Applied Sciences, Amsterdam, The Netherlands

\section{Correspondence}

Jimmy Frerejean, School of Health Professions Education, Faculty of Health, Medicine and Life Sciences, Maastricht University, Universiteitssingel 60 Maastricht 6229 ER, The Netherlands. Email: j.frerejean@maastrichtuniversity.nl

\begin{abstract}
Objectives-based instructional design approaches break down tasks into specific learning objectives and prescribe that instructors should choose the optimal instructional method for teaching each respective objective until all objectives have been taught. This approach is appropriate for many tasks where there is little relation between the objectives, but less effective for teaching complex professional tasks that require the integration of knowledge, skills, and attitudes and the coordination of different skills. For the latter, a task-centred approach that starts designing instruction from whole, real-life tasks, is more appropriate. This article describes one task-centred instructional design model, namely the FourComponent Instructional Design (4C/ID) model and illustrates its application by reflecting on three educational programs in higher education designed with 4C/ID. The first case presents a design for a course that focuses on the development of mobile apps at the Amsterdam University of Applied Sciences in the Netherlands. The second case illustrates the integration of information problem-solving skills at Iselinge University of Professional Teacher Education, a teacher training institute in the Netherlands. The third case is an example from general practice education at the KU Leuven, Belgium. Future developments and issues concerning the implementation of taskcentred educational programmes are discussed.
\end{abstract}




\section{1 | INTRODUCTION}

Continuing technological and societal innovations create high demands on the field of education. In order to deal with increasing globalisation, multidisciplinarity, mobility and the complexity of current and future jobs, a strong emphasis is placed on the quality and efficiency of all levels of education and training (European Union, 2009,2018). To prepare learners for a job market that is continually evolving, it is imperative that educational programmes provide them with an extensive knowledge and skills base that they can apply flexibly when encountering unfamiliar tasks in daily practice. This is reflected in the increasing call for competency-based and outcome-based education. Since the 1990s, the balance in educational approaches has been shifting away from objectives-based instructional design approaches towards more task-centred approaches in an attempt to better address the learning of complex cognitive skills and professional competencies (Gagné \& Merrill, 1990; Merrill, Li, \& Jones, 1990).

The objectives-based approach breaks down tasks into their constituent parts and describes desired outcomes for each of these part-tasks in learning objectives which are often classified according to a taxonomy such as Bloom's revised taxonomy (Anderson \& Krathwohl, 2001) or Marzano and Kendall's taxonomy (2007). Bloom's revised taxonomy, for example, classifies objectives in the cognitive domain in six categories based on remembering, understanding, applying, analysing, evaluating and creating. These taxonomies result from the idea that different instructional methods are needed to reach objectives in different categories. Teaching concepts and principles (e.g., understanding what a scientific paper is and how it is structured) requires different instructional methods from teaching the application of procedures (e.g., carrying out a literature search for a paper). This idea of "conditions of learning" (Gagné, 1985) means that instructors should choose the optimal instructional method for each respective objective and teach according to the chosen method until all the objectives have been taught. It is only at the end of the educational programme that students have the opportunity to train and execute the whole task in an integrated fashion (e.g., when writing a thesis). This objectives-based approach is suitable for tasks where there are few relations between the objectives. However, it is less effective for those that require an integration of knowledge, skills and attitudes and the coordination of sometimes many different constituent skills (van Merriënboer \& Dolmans, 2015). First, the compartmentalisation of learning into separate categories of objectives and using separate methods for declarative, procedural and affective learning is ineffective because carrying out a complex professional task requires more than just the stacking of these constituent elements. Instead, carrying out complex tasks generally requires an integration of knowledge, skills and attitudes in so-called competencies. Instruction should therefore focus on developing an interconnected knowledge base that allows one to activate different kinds of knowledge when confronted with new and unfamiliar tasks (Janssen-Noordman, van Merriënboer, van der Vleuten, \& Scherpbier, 2006).

Second, the objectives-based approach of teaching complex skills leads to fragmentation. Because it breaks up the complex tasks into separate isolated parts, students only learn a limited number of skills at the same time. Instruction is focused on parts of the task and provides little opportunity to learn how to coordinate the performance of these separate parts into a coherent whole when confronted with a professional task (Lim, Reiser, \& Olina, 2009). In an attempt to address these problems of fragmentation and compartmentalisation, task-centred approaches centre learning on whole real-world (i.e., authentic) problems or professional tasks as a way to better connect the learning setting to the workplace setting and foster the necessary skills. This holistic approach advocates creating educational programmes that contain sequences of learning tasks that are based on authentic professional tasks. Examples of task-centred models are cognitive apprenticeship (Brown, Collins, \& Duguid, 1989), elaboration theory (Reigeluth, 1999), first principles of instruction (Merrill, 2002) and the four-component instructional design model (4C/ID model) (van Merriënboer, 1997). The 4C/ID model is characterised by a strong research base and a spreading popularity, as evidenced by the increasing number of publications in various contexts, such as medical education (Maggio, Cate, Irby, \& O'Brien, 2015), communications training (Susilo, van Merriënboer, van Dalen, Claramita, \& Scherpbier, 2013), technical training (Sarfo \& Elen, 2007), information 
problem-solving (Wopereis, Frerejean, \& Brand-Gruwel, 2015), and teacher training (Kreutz, Leuders, \& Hellmann, 2019). The accompanying Ten Steps approach (van Merriënboer \& Kirschner, 2018) provides guidelines for analysing real-life tasks in order to uncover the different types of knowledge and skills needed in daily practice (cognitive task analysis) and guidelines for designing a blueprint for an educational programme comprising four components: learning tasks, supportive information, procedural information and part-task practice.

This article provides a brief summary of the model and illustrates its application in higher education by describing three educational programmes that were designed using the 4C/ID model. The first case presents a design for a course focusing on the development of mobile apps at the Amsterdam University of Applied Sciences in the Netherlands. The second illustrates the integration of information problem-solving skills at Iselinge University of Professional Teacher Education, a teacher training institute in the Netherlands. The third is an example from general practice education at the KU Leuven, Belgium. The article concludes with a short reflection on the educational programmes that were developed, a list of important considerations for implementing task-centred curricula and a look at future developments in task-centred learning.

\section{FOUR-COMPONENT INSTRUCTIONAL DESIGN (4C/ID)}

The basic assumption of the 4C/ID model is that educational programmes for complex learning or the teaching of professional competencies (i.e., the integration of knowledge, skills, and attitudes and coordination of skills and their constituents) can be described in four components, namely learning tasks, supportive information, procedural information and part-task practice (see Figure 1).

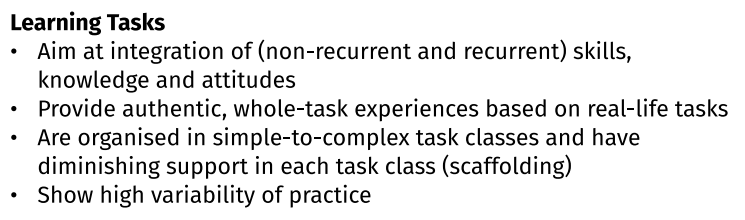

\section{Part-task Practice}

- Provides additional practice for selected recurrent aspects to reach a very high level of automaticity

- Provides a huge amount of repetition

- Only starts after the recurrent aspect has been introduced in the context of the whole task

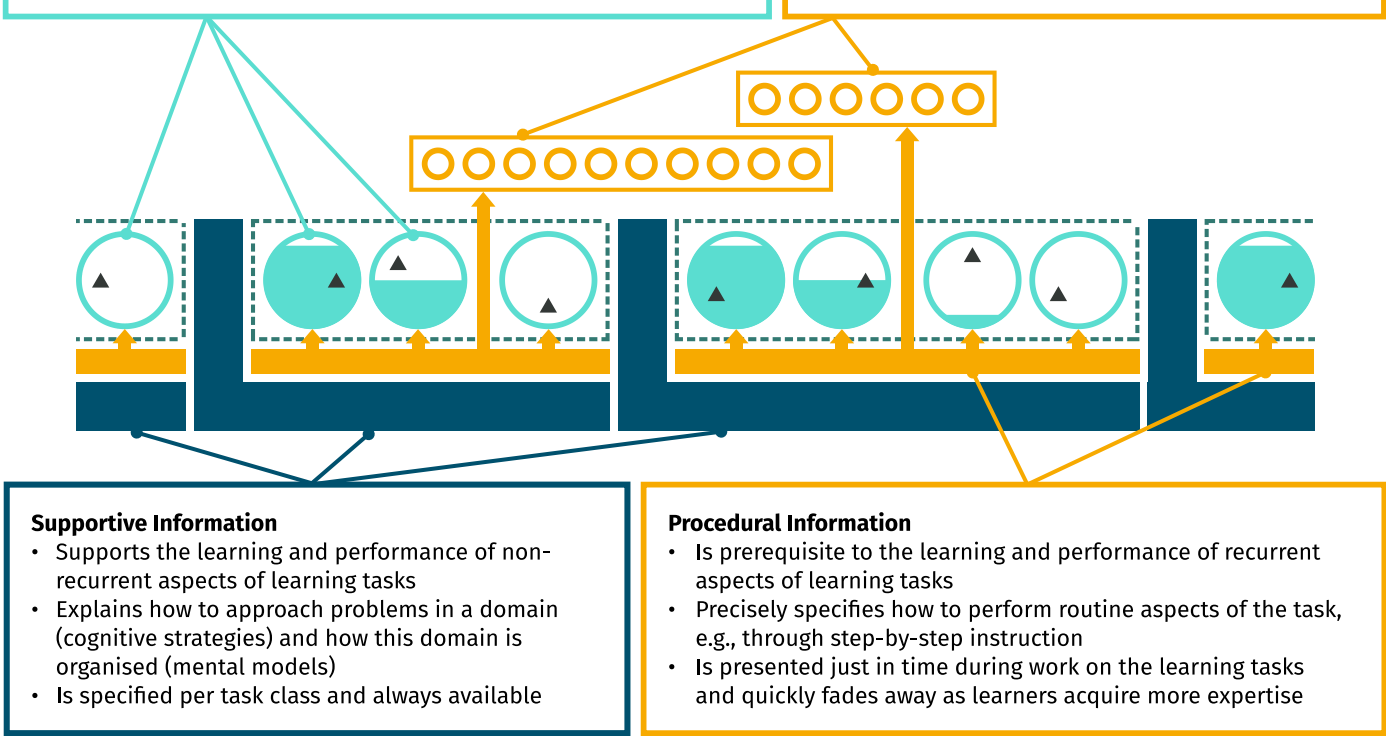

FIG URE 1 Overview of 4C/ID model, based on Van Merriënboer and Kirschner (2018) [Colour figure can be viewed at wileyonlinelibrary.com] 
Learning tasks form the backbone of the instructional blueprint and are based on authentic real-life situations that are encountered in practice because this helps the learner to acquire the knowledge, skills and attitudes in an integrated fashion. Learning tasks can be projects, tasks, cases, problems, or other types of assignments. Importantly, they show a variation that is representative of the variation in tasks in professional or daily life because this "variability of practice" will help in the transfer of learning. Learning tasks of equal complexity are grouped together, creating task classes that are sequenced from simple to complex. Learners start with the task class that contains the simplest tasks that a professional could encounter and end with the task class that contains tasks at the level of complexity that a recently-graduated student should be able to handle (van Merriënboer, Kirschner, \& Kester, 2003). While working on these tasks, the teacher and the instructional materials provide the necessary support and guidance to help learners to carry out the tasks to completion. In a process of scaffolding, this support and guidance are gradually withdrawn until the learners are able to independently carry out tasks of a certain level of complexity before engaging in more complex tasks (i.e., the next task class). The three other components are logically connected to this backbone of learning tasks.

While Figure 1 may suggest a linear path through these learning tasks, the model allows for extensive flexibilisation and personalisation of learning trajectories. Learners may be given the opportunity to select different paths through the designed learning tasks, based on their interest or demonstrated proficiency. One way to support this dynamic selection is by using electronic development portfolios that help students and teachers to monitor progress and make informed decisions on future learning tasks that fit the learner's level and needs (Beckers, Dolmans, \& van Merriënboer, 2019; Kicken, Brand-Gruwel, van Merriënboer, \& Slot, 2009).

The second component, supportive information, is often referred to as "the theory" and includes information to develop mental models and cognitive strategies that are necessary to complete the learning tasks. Supportive information aims at non-recurrent aspects of the task that deal with problem-solving, reasoning and decision making. It can be presented in the form of lectures, workshops, or study materials and is available for students to study before or while they carry out the learning tasks. These first two components help students to acquire highly-structured knowledge, or cognitive schemas. Learning tasks stimulate the construction of such schemas through inductive learning: a process whereby students learn from mindful abstraction from concrete experiences and examples. Supportive information helps schema construction by elaboration: acquiring new knowledge and linking it to the existing knowledge base.

The remaining two components stimulate the automation of schemas and the development of automatic, taskspecific procedures that can be applied without much demand on cognitive processing resources. Procedural information aims at recurrent and procedural aspects and provides step-by-step instructions when the learner performs those aspects. Part-task practice, the fourth component, can be included to provide repeated practice to train routine skills until they can be performed automatically. (For a more extensive description of the model, see van Merriënboer, 1997; van Merriënboer et al., 2003; or van Merriënboer \& Kirschner, 2018).

\section{A 4C/ID APPROACH TO A BLENDED COURSE IN ANDROID APP DEVELOPMENT}

Developing mobile applications is a typical complex skill, as it requires extensive knowledge of programming languages, databases, development environments, etc. It also requires multiple skills, such as operating the development software, writing clean and correct codes, and/or designing a user interface. A professional, critical and creative attitude is necessary to translate clients' wishes into a working application. Therefore the development of mobile applications lends itself well to teaching with a task-centred approach. The Amsterdam University of Applied Sciences in the Netherlands designed a course on Android app development using the 4C/ID model (www.android-development.app). 
Traditionally, the design of such courses starts from the "theory". Teachers begin with a clear picture of the information their students should know and design a series of lectures to "transmit" this theory to the students. In addition, they design homework assignments to practise with single, small aspects of the whole task. For example, these assignments could focus on how to use loops in the programming language or creating, reading, updating, and deleting information in a database. Teachers then mix lectures with small practice items until all topics have been covered. This follows the approach of traditional design models: starting with the presentation of theoretical knowledge and coupling it to specific practice items. The 4C/ID model topples this approach: it starts by specifying professional tasks, translates these into learning tasks and only then investigates which "theory" should help students to complete these learning tasks.

In their description of the design of the course, Marcellis, Barendsen, and van Merriënboer (2018) elaborate on the use of 4C/ID and the Ten Steps to achieve a blended design consisting of the four components. The learning tasks form the backbone of the curriculum. These are not small practice items focused on a particular aspect of the task (i.e., using loops or updating a database). Instead, learning tasks are whole tasks, based on professional practice, grouped in task classes that grow in complexity. The first task class starts with the least complex (i.e., simplest) whole tasks. For example, the very first task asks the student to develop a single-screen app that simulates a dice roll and asks the user to guess whether the next roll will be higher or lower. Subsequent task classes include learning tasks of increasing complexity, imposing more demands on the user interface, interaction modes and handling of data. At the end of the course, students are asked to create multi-screen applications that retrieve information (e.g., movie information, recipes) from remote locations and allow the user to view, swipe, and manipulate these data.

Students receive strong support and guidance when starting learning tasks in a new and more complex task class. The design achieves this by employing modelling examples and imitation tasks at the start of each task class. The teacher demonstrates the development of an application while thinking aloud and asks students to build an identical application on their computers. In subsequent tasks, students receive partially-completed applications they must finish (i.e., completion tasks), while the final tasks in a task class are conventional tasks without any support and guidance. Hence, support gradually decreases as the student progresses through the task class.

Supportive information helps students with the non-recurrent aspects of the task by providing domain knowledge (e.g., how databases work) and systematic approaches to developing apps (e.g., demonstrations by the teacher). Procedural information helps with the recurrent aspects (e.g., using the development environment or automatic highlighting of incorrect programming syntax). For the designers, providing supportive and procedural information constituted a serious challenge, as both are subject to frequent and unpredictable changes. For example, development software is frequently updated with changed functionality and programming languages continually evolve, requiring programmers to learn new syntax and unlearn old methods. To make sure that the supportive and procedural information reflect the most recent conventions and rules in the domain, the course designers depended less on pre-prepared lectures or recorded videos and instead referred students to a list of external sources, including manuals and Android developer documentation. Not only is it easier to keep a list of links up to date, it also creates a more authentic situation where students learn to study official documentation, as they would do in practice.

As the course is intended for students from all over the world who are studying full-time or part-time, the designers chose a blended design where learning tasks, supportive information and procedural information resided in an online learning environment. Classroom activities can be followed by students on-site and include modelling examples, imitation tasks in small groups and feedback sessions led by the teacher. Other learning tasks are presented in the online learning environment and are performed individually by students. Student evaluations show that students perceive the learning tasks as very helpful for learning how to develop an Android app. The modelling examples specifically contribute to understanding how to approach a certain challenge in Android app development, especially when they not only show the actual coding, but also make explicit the reasoning behind each step. In addition, students perceive the classroom sessions in which they discuss theory using guided questions 
as beneficial. This Android app development course illustrates a well-executed application of fundamental 4C/ID principles leading to a course design that is strongly informed by educational research.

\section{A 4C/ID APPROACH TO TEACHING INFORMATION PROBLEM- SOLVING SKILLS}

This next case is from a teacher training institute in the Netherlands that addresses the lack of information problem-solving (IPS) skills training in their curriculum. Students need IPS skills to search for and use information from online sources for educational purposes. When presented with a problem for which information must be collected online, a successful IPS process entails creating a clear definition of the problem, systematically searching for information, evaluating and selecting sources, critically reading and processing the information in those sources and synthesising the information to find a solution to the problem (Brand-Gruwel, Wopereis, \& Walraven, 2009). A complex skill with which students of all ages struggle (Walraven, Brand-Gruwel, \& Boshuizen, 2008). While this need for well-developed IPS skills is often recognised, educational institutions seem to struggle to find the best way to integrate IPS instruction in their curricula (Badke, 2011).

Objectives-based instructional design thinking may lead the institute to use separate IPS training sessions, modules, or assignments focusing on developing general IPS skills, often provided by the university library. While they may show short term gains, these approaches often teach IPS skills out of context of the domain-specific field where students will be using them. A student is not really able to effectively generate search terms and evaluate sources without sufficient knowledge of the domain in which the search takes place. This compartmentalised approach focuses on teaching a set of skills separately from teaching the very important domain-specific knowledge. Students have little opportunity to practise their IPS skills in the context where they will be needing it. This illustrates how a compartmentalised approach hinders the integration of the knowledge, skills and attitudes that are necessary for complex learning.

Another approach may lead the institute to address the different constituent skills in different courses. Language courses may address how to critically read and evaluate sources, informatics courses may address how to use search engines to search for information and research courses may teach students how to define a problem and ask questions. This, however, constitutes a fragmented approach where none of the skills needed for IPS are taught simultaneously. Students confronted with a problem that requires all the constituent IPS skills might struggle because they have only learned to carry out the skills separately and never practised coordinating the different skills in a complex task. This illustrates how a fragmented approach hinders the coordination of skills and their constituent skills that are necessary for complex learning.

Instead, a whole-task approach using 4C/ID promises a better approach to deal with the disadvantages of compartmentalised and fragmented approaches. The institute decided to embed a task-centred IPS training in a semester-long course on language teaching for primary school teachers. The original curriculum consisted of a 20-week course focused on language education for primary school children with an emphasis on vocabulary development. In a project-based approach, the course involved groupwork in which students conducted a small experiment and compared different interventions to develop vocabulary in the classroom. Students attended six face-to-face classroom sessions addressing the necessary domain-specific knowledge about language learning and vocabulary development and research skills, such as conducting the literature study, designing the intervention, data analysis and writing the report. The groups received a template document to record the research proposal for which they received feedback. To embed additional IPS skills training into the course, a second blueprint was designed, describing a series of online learning tasks including supportive and procedural information, aimed at teaching IPS skills in the context of vocabulary development. This blueprint was subsequently intertwined with the original course. This resulted in a course with alternating face-to-face and online learning tasks. After two face-to-face sessions that explained the research project and introduced theory about vocabulary education, 
students were required to carry out a series of online tasks aimed at IPS skills. These tasks included a video modelling example demonstrating an effective web search on the effects of reading aloud on primary school children's vocabulary development and two tasks in which the students received partially worked-out search tasks they had to complete to find answers to questions dealing with teaching strategies for good vocabulary education and the relationship between vocabulary size and school success. Answers to these questions were then discussed in a group discussion during the following face-to-face meeting. This approach, alternating between online learning tasks and face-to-face sessions, continued until the end of the course at which point the students had completed five online learning tasks and attended one additional face-to-face session specifically addressing feedback on their IPS skills.

Frerejean, Velthorst, van Strien, Kirschner, and Brand-Gruwel (2019) described the curriculum in detail and compared it with the original course without explicit IPS training. Results showed that the embedded instruction was effective to develop systematic searching and selecting of sources, but these improvements disappeared after completing the course. This is not surprising, as learning complex skills takes time and requires longer practice. Traditional designs choose instructional methods to reach specific, isolated learning goals as efficiently as possible. Yet these methods often differ from those that are best for reaching integration, coordination and the transfer of learning to new settings. This phenomenon is known as the transfer paradox (Helsdingen, van Gog, \& van Merriënboer, 2011; van Merriënboer, de Croock, \& Jelsma, 1997) which is strongly related to the concept of desirable difficulties: creating learning tasks that require considerable effort, but lead to better long-term performance than easier tasks (desirable difficulties; Bjork, 1994). In conclusion, using a task-centred approach to complex learning could seem less efficient because it can require more learning activities-and thus more time-than a traditional design, but when implemented correctly, it will lead to better transfer to new settings.

\section{5 | A 4C/ID APPROACH TO BLENDED LEARNING MODULES FOR GENERAL PRACTICE}

For medical educators, the Canadian Medical Education Directives for Specialists (CanMEDS); (Frank \& Danoff, 2007) describe the abilities that physicians need to effectively meet the health care needs of those they serve. These competencies are grouped in a framework consisting of seven roles: medical expert, communicator, collaborator, leader, health advocate, scholar and professional. The competent physician is expected to integrate the competencies of all seven CanMEDS roles. Such frameworks describe standards that should be met by the learners and allow for the organisation of curricula around competency-based learning outcomes. This presents a prime example of complex learning where knowledge, skills and attitudes must be integrated, as students are expected to be able to integrate the different competencies and coordinate the different CanMEDS roles.

The KU Leuven also uses the CanMEDS framework as the backbone for its medical education curriculum. In their AMEE Guide, Vandewaetere et al. (2015) describe how they designed five learning modules based on the CanMEDS framework using the 4C/ID model (https://med.kuleuven.be/nl/levensechtleren). Similar to designers in the previous examples, they make the case for whole-task learning to achieve the integrated acquisition of knowledge, skills and attitudes. They repeat that whole-task models provide a solid framework for developing learning activities that foster complex learning and support transfer from the curriculum to the workplace and they value the evidence-based principles underlying 4C/ID.

Their modules present learning tasks that are carried out during the course and learning tasks that are carried out in the workplace during the student's internship. Course tasks are whole tasks that are a reflection of the general practitioner's daily practice and can take many forms, such as case diagnoses, commenting on a scientific article, developing information leaflets for patients, role plays, discussions with patients, spot diagnoses, or presentations to colleagues. They can be presented in individual, computer-based tasks (e.g., computerised self-assessment tests), group tasks (e.g., online presentation of a mock patient or case to be studied before coming 
to the group session in which the case will be discussed) and face-to-face classes in which the instructor provides feedback, answers any questions or elaborates on complex topics. In line with 4C/ID principles, learning tasks are grouped in task classes and sequenced from simple to complex. In each task class, support and guidance gradually decrease as the learner progresses through the tasks. The workplace-based learning tasks are often carried out in collaboration with supervisors and medical experts and can take the form of observing and reflecting on history taking, participating in multidisciplinary team meetings, or writing prescriptions.

In these modules, the supportive information contains materials that help to acquire domain knowledge, such as illness scripts or treatment protocols and help to form cognitive strategies, such as systematic approaches and rules-of-thumb for clinical reasoning. The supportive information is presented in several ways. At the beginning of the task class, students receive a worked example, such as a video of a consultation or a demonstration of a motivational interview. They are encouraged to reflect on the application of cognitive strategies and domain knowledge in the demonstration. After the example, more study materials are presented, such as lectures, course documents and research articles. Supportive information is also presented in the form of cognitive feedback after the completion of learning tasks. In this case, students receive feedback on their task performance that relates to the mental models and cognitive strategies presented earlier. Specific reflection prompts are included that encourage students to reflect on an expert's or a peer's performance or to self-reflect. Such prompts function as a mechanism to enhance feedback and simultaneously trigger self-regulated learning behaviour.

For recurrent aspects of task performance, procedural information such as manuals, checklists, quick reference guides and job aids is available during the learning tasks. For example, when first accessing a patient's health record, a step-by-step procedure is presented telling the student where to click and which information to provide. This information gradually fades away as the student's skill increases. In addition, the corrective feedback provided on routine aspects of the tasks becomes less elaborate as the student progresses through the programme. The designers also included part-task practice in the programme. In medical education, such repeated practice can be useful to automate routine tasks such as measuring blood pressure, suturing, or carrying out CPR. But it can also be applied to important aspects of the consultation, such as spot diagnoses. Correct spot diagnosis requires quick recognition of relevant symptoms, exclusion of irrelevant symptoms and identification of the next steps of the diagnostic reasoning process (Vandewaetere et al., 2015, p. 14). In one module, this part-task practice is implemented in the form of online quizzes with photos of childhood rashes and several multiple-choice questions with immediate feedback.

The design of these modules demonstrates two types of blended learning. First, it uses a variety of traditional media and newer online media. In an approach that mimics the "flipped classroom" (O'Flaherty \& Phillips, 2015), much of the content delivery that traditionally takes place in the classroom now takes place outside the classroom and the application of content that traditionally takes place at home is now moved to the classroom. In other words, much of the supportive information is studied at home, whilst work on the learning tasks is conducted faceto-face. A particularly interesting point is that the designers make great use of online quizzes or self-assessments, a practice associated with effective and attractive blended learning (Spanjers et al., 2015). In a second blend, the programme combines learning tasks in an educational setting with learning tasks in the workplace. From this perspective, the design by Vandewaetere et al. (2015) provides an interesting example of a double-blended learning programme.

\section{CONCLUSION}

The three cases all demonstrate interesting applications of task-centred instructional design using the 4C/ID model. In addition, each case shows an interesting distinct feature. The first illustrates how 4C/ID was used to create a series of authentic learning tasks and provide this in an online learning environment, stimulating blended 
learning by combining face-to-face and online learning. The second shows how a training for domain-general skills (i.e., information problem-solving skills) can be embedded in a domain-specific programme by designing learning tasks around finding and retrieving supportive information. The final case provides an example of a doubleblended programme that blends online and face-to-face learning with learning tasks in both the school setting and the workplace. However, throughout the examples, the common theme is the shift of balance from the atomistic, compartmentalised and fragmented teaching of isolated objectives towards integrative acquisition of knowledge, skills and attitudes.

Designing educational programmes using the 4C/ID model is different from designing using objectives-based approaches. It requires task-centred thinking which may be challenging for designers, teachers and faculty who are schooled and experienced in objectives-based instructional design. The 4C/ID model is well-aligned with the concept of competency-based education, but it stresses that competencies should always be clearly related to the professional tasks the student is expected to carry out after completing the programme. An educational programme taking a competency framework as a backbone for its development and assessment may still hamper the transfer of learning to the workplace if the learning activities in that programme are not strongly based on professional tasks. Designing task-centred learning environments therefore requires assigning equal weight to tasks on the one hand and to the competencies required to carry out these tasks on the other. The Ten Steps approach starts the design by specifying professional tasks to serve as a basis for designing learning tasks. The professional and learning tasks are then explicitly linked to the competencies that are necessary to carry out those tasks up to standards, for example by generating a matrix with tasks at one end and competencies or standards at the other.

Concerning the design and implementation of task-centred curricula, Dolmans, Wolfhagen, and van Merriënboer (2013) identify 12 common pitfalls and tips that may help to make such (re)designs work. The four most significant deal with building infrastructure, multidisciplinary teaching teams, continuous progress monitoring and involving students. First, in task-centred designs, a series of whole-tasks forms the backbone of the programme. Therefore, the main educational activities consist of small group meetings in which students collaboratively work on these learning tasks. To facilitate this, there should be sufficient small group rooms available that are equipped with all the necessities such as whiteboards, projectors, and high-speed wireless Internet. Other facilities could be necessary, such as lecture halls, simulation labs, or individual reading and studying rooms, but they are present in most schools. It is more often the lack of sufficient small group rooms that impedes the implementation of task-centred learning.

Secondly, task-centred curricula require the design of a series of learning tasks for an integrative acquisition of knowledge, skills and attitudes. Content that was previously taught separately by different teachers must now be taught in an integrated fashion and teachers should therefore work together in multidisciplinary teams that preferably also include outside domain experts working in the field. These experts can help to align the educational programme with practice and ensure the relevance of the tasks, tools and required knowledge. Teaching staff should also be prepared to adopt different roles, as teachers in task-centred curricula generally have a tutoring or coaching role in order to facilitate small group learning or skills training. They may also be involved in whole-task design and continuous assessment. If teachers are unfamiliar with these new roles, faculty development programmes may be needed to prepare staff members for this change.

Thirdly, in the Ten Steps approach, the assessment programme is developed simultaneously with the design of learning tasks because assessment drives learning. In a task-centred curriculum, assessment should not be used solely for making pass/fail decisions for separate courses. Instead, it should allow for the monitoring of individual student progress at the level of the whole curriculum. This can be done by using electronic development portfolios that combine multiple assessment results and provide a dashboard that informs both students and teachers of the students' progress and improvement. This approach no longer relies on traditional assessment arrangements, such as fixed-length semesters with pre-planned exam weeks.

Lastly, students themselves should play an important role in the design of the whole curriculum and of individual learning tasks. Involving students in the design process provides valuable insights into the curriculum's 
strengths and weaknesses, as they are the only ones to experience the curriculum. As it is crucial that students experience the learning tasks as meaningful and useful, their perceptions are very informative for designers. Thoroughly informing students of the ideas behind the task-centred curriculum may also benefit implementation, as those students can become advocates of the reform. Furthermore, just as teachers have different roles in a task-centred curriculum, students also need to be prepared for their new roles. They need to function in small group meetings and learn how to actively contribute to group discussions, how to act as group leaders or scribes and how to provide effective feedback to peers. As is the case with faculty development, such student training preferably extends over a prolonged period.

To conclude, dealing with current and future developments in the job market requires that educational programmes produce lifelong learners who are equipped with the knowledge, skills and attitudes to deal with familiar and unfamiliar complex tasks in their domain. The way these programmes are designed must therefore match this goal of creating learners who are able to transfer their knowledge from the learning to the professional setting. Task-centred instructional design models such as the 4C/ID model stimulate this process by prescribing learning methods that lead to a rich knowledge base allowing for creative applications of knowledge in new and innovative settings. Additionally, they create a strong alignment between education and practice by blending learning in the educational setting with learning in the workplace. This encourages cross-institutional and international collaboration when designing educational programmes, which is especially important in those settings where tasks require international and interdisciplinary work, such as the banking, aviation, or tech sector. A clear implication for educational policy is that collaboration between employers and higher education must be strengthened: $A$ two-way interaction is needed where educational institutions not only prepare students for the job market, but where employers also bring state-of-the art knowledge, future job requirements and tasks to the educational institutions.

\section{7 | FUTURE DEVELOPMENTS}

In the book Ten Steps to Complex Learning, van Merriënboer and Kirschner (2018) present an extensive systematic approach to design task-centred educational programmes with the 4C/ID model, based on evidence from research on education and learning going back to the late 1980s. They also identify several important directions for advancing the model. Future developments will focus on the integration of new educational technologies (e.g., blended programmes, gamification), dealing with large learner groups (e.g., learning analytics, customisation), teaching domain-generalisable skills (e.g., intertwining domain-general and domain-specific programmes) and promoting motivation and preventing negative emotions. With research on these topics now maturing, designers can look forward to an expanded set of guidelines to design effective, efficient, and enjoyable programmes for complex learning.

\section{REFERENCES}

Anderson, L. W., \& Krathwohl, D. R. (Eds.). (2001). A taxonomy for learning, teaching, and assessing: A revision of Bloom's taxonomy of educational objectives. New York, NY: Longman.

Badke, W. (2011). Why information literacy is invisible. Communications in Information Literacy, 4, 129-141. https://doi. org/10.15760/comminfolit.2011.4.2.92

Beckers, J., Dolmans, D. H. J. M., \& van Merriënboer, J. J. G. (2019). PERFLECT: Design and evaluation of an electronic development portfolio aimed at supporting self-directed learning. TechTrends, 63, 420-427. https://doi.org/10.1007/ s11528-018-0354-x

Bjork, R. A. (1994). Memory and metamemory considerations in the training of human beings. In J. Metcalfe \& A. P. Shimamura (Eds.), Metacognition: Knowing about knowing (pp. 185-205). Cambridge, MA: MIT Press.

Brand-Gruwel, S., Wopereis, I., \& Walraven, A. (2009). A descriptive model of information problem solving while using internet. Computers \& Education, 53, 1207-1217. https://doi.org/10.1016/j.compedu.2009.06.004 
Brown, J. S., Collins, A., \& Duguid, P. (1989). Situated cognition and the culture of learning. Educational Researcher, 18, 32-42. https://doi.org/10.3102/0013189X018001032

Dolmans, D. H. J. M., Wolfhagen, I. H. A. P., \& van Merriënboer, J. J. G. (2013). Twelve tips for implementing whole-task curricula: How to make it work. Medical Teacher, 35, 801-805. https://doi.org/10.3109/0142159X.2013.799640

European Union. (2009). Council conclusions of 12 May 2009 on a strategic framework for European cooperation in education and training (ET 2020) (2009). Official Journal of the European Union, C119, 2-10.

European Union. (2018). Council recommendation of 22 May 2018 on key competences for lifelong learning (2018). Official Journal of the European Union, C189, 1-13.

Frank, J. R., \& Danoff, D. (2007). The CanMEDS initiative: Implementing an outcomes-based framework of physician competencies. Medical Teacher, 29, 642-647. https://doi.org/10.1080/01421590701746983

Frerejean, J., Velthorst, G. J., van Strien, J. L. H., Kirschner, P. A., \& Brand-Gruwel, S. (2019). Embedded instruction to learn information problem solving: Effects of a whole task approach. Computers in Human Behavior, 90, 117-130. https://doi.org/10.1016/j.chb.2018.08.043

Gagné, R. M. (1985). The conditions of learning and theory of instruction (4th ed.). New York, NY: Holt, Rinehart and Winston.

Gagné, R. M., \& Merrill, M. D. (1990). Integrative goals for instructional design. Educational Technology Research and Development, 38, 23-30. https://doi.org/10.1007/BF02298245

Helsdingen, A. S., van Gog, T., \& van Merriënboer, J. J. G. (2011). The effects of practice schedule on learning a complex judgment task. Learning and Instruction, 21, 126-136. https://doi.org/10.1016/j.learninstruc.2009.12.001

Janssen-Noordman, A. M. B., van Merriënboer, J. J. G., van der Vleuten, C. P. M., \& Scherpbier, A. J. J. A. (2006). Design of integrated practice for learning professional competences. Medical Teacher, 28, 447-452. https://doi. org/10.1080/01421590600825276

Kicken, W., Brand-Gruwel, S., van Merriënboer, J. J. G., \& Slot, W. (2009). Design and evaluation of a development portfolio: How to improve students' self-directed learning skills. Instructional Science, 37, 453-473. https://doi.org/10.1007/ s11251-008-9058-5

Kreutz, J., Leuders, T., \& Hellmann, K. (2019). Professionsorientierung in der Lehrerbildung: Kompetenzorientiertes Lehren nach dem 4-Component-Instructional-Design-Modell. Wiesbaden, Germany: Springer Fachmedien Wiesbaden.

Lim, J., Reiser, R. A., \& Olina, Z. (2009). The effects of part-task and whole-task instructional approaches on acquisition and transfer of a complex cognitive skill. Educational Technology Research and Development, 57, 61-77. https://doi. org/10.1007/s11423-007-9085-y

Maggio, L. A., Cate, O. T., Irby, D. M., \& O’Brien, B. C. (2015). Designing evidence-based medicine training to optimize the transfer of skills from the classroom to clinical practice: Applying the four component instructional design model. Academic Medicine, 90, 1457-1461. https://doi.org/10.1097/ACM.0000000000000769

Marcellis, M., Barendsen, E., \& van Merriënboer, J. J. G. (2018). Designing a blended course in android app development using 4C/ID. In Proceedings of the 18th Koli Calling International Conference on Computing Education Research (Koli Calling '18) (pp. 1-5). Koli, Finland: ACM Press. https://doi.org/10.1145/3279720.3279739

Marzano, R. J., \& Kendall, J. S. (2007). The new taxonomy of educational objectives (2nd ed.). Thousand Oaks, CA: Corwin Press.

Merrill, M. D. (2002). First principles of instruction. Educational Technology Research and Development, 50, 43-59. https:// doi.org/10.1007/BF02505024

Merrill, M. D., Li, Z., \& Jones, M. K. (1990). Second generation instructional design. Educational Technology, 30, 7-14.

O'Flaherty, J., \& Phillips, C. (2015). The use of flipped classrooms in higher education: A scoping review. The Internet and Higher Education, 25, 85-95. https://doi.org/10.1016/j.iheduc.2015.02.002

Reigeluth, C. M. (1999). The elaboration theory: Guidance for scope and sequence decisions. In C. M. Reigeluth (Ed.), Instructional-design theories and models: A new paradigm of instructional theory, Vol II (pp. 425-453). Mahwah, NJ: Lawrence Erlbaum Associates Publishers.

Sarfo, F. K., \& Elen, J. (2007). Developing technical expertise in secondary technical schools: The effect of 4C/ID learning environments. Learning Environments Research, 10, 207-221. https://doi.org/10.1007/s10984-007-9031-2

Spanjers, I. A. E., Könings, K. D., Leppink, J., Verstegen, D. M. L., de Jong, N., Czabanowska, K., \& van Merriënboer, J. J. G. (2015). The promised land of blended learning: Quizzes as a moderator. Educational Research Review, 15, 59-74. https://doi.org/10.1016/j.edurev.2015.05.001

Susilo, A. P., van Merriënboer, J. J. G., van Dalen, J., Claramita, M., \& Scherpbier, A. (2013). From lecture to learning tasks: Use of the 4C/ID model in a communication skills course in a continuing professional education context. The Journal of Continuing Education in Nursing, 44, 278-284. https://doi.org/10.3928/00220124-20130501-78

van Merriënboer, J. J. G. (1997). Training complex cognitive skills: A four-component instructional design model for technical training. Englewood Cliffs, NJ: Educational Technology Publications.

van Merriënboer, J. J. G., de Croock, M. B. M., \& Jelsma, O. (1997). The transfer paradox: Effects of contextual interference on retention and transfer performance of a complex cognitive skill. Perceptual and Motor Skills, 84, 784-786. https://doi.org/10.2466/pms.1997.84.3.784 
van Merriënboer, J. J. G., \& Dolmans, D. H. J. M. (2015). Research on instructional design in the health sciences: From taxonomies of learning to whole-task models. In J. Cleland \& S. J. Durning (Eds.), Researching medical education (pp. 193-206). Chichester, UK: John Wiley \& Sons, Ltd.

van Merriënboer, J. J. G., \& Kirschner, P. A. (2018). Ten steps to complex learning: A systematic approach to four-component instructional design (3rd ed.). New York, NY: Routledge.

van Merriënboer, J. J. G., Kirschner, P. A., \& Kester, L. (2003). Taking the load off a learner's mind: Instructional design for complex learning. Educational Psychologist, 38, 5-13. https://doi.org/10.1207/S15326985EP3801_2

Vandewaetere, M., Manhaeve, D., Aertgeerts, B., Clarebout, G., van Merriënboer, J. J. G., \& Roex, A. (2015). 4C/ID in medical education: How to design an educational program based on whole-task learning: AMEE Guide No. 93. Medical Teacher, 37, 4-20. https://doi.org/10.3109/0142159X.2014.928407

Walraven, A., Brand-Gruwel, S., \& Boshuizen, H. P. A. (2008). Information-problem solving: A review of problems students encounter and instructional solutions. Computers in Human Behavior, 24, 623-648. https://doi.org/10.1016/j. chb.2007.01.030

Wopereis, I., Frerejean, J., \& Brand-Gruwel, S. (2015). Information problem solving instruction in higher education: A case study on instructional design. In S. Kurbanoglu, J. Boustany, S. Špiranec, E. Grassian, D. Mizrachi, \& L. Roy (Eds.), Information literacy: Moving toward Sustainability. (Vol. 552, pp. 293-302). Basel, Switzerland: Springer.

How to cite this article: Frerejean J, van Merriënboer JJG, Kirschner PA, Roex A, Aertgeerts B, Marcellis M. Designing instruction for complex learning: 4C/ID in higher education. Eur J Educ. 2019;54:513-524. https://doi.org/10.1111/ejed.12363 